\title{
Differential skin conductance condition as a function of interstimulus interval*
}

\author{
WILLIAM R. JENSON $\dagger$ and WILLIAM F. PROKASY \\ University of Utah, Salt Lake City, Utah 84112
}

Three groups of Ss were given differential skin conductance classical conditioning trials at interstimulus intervals of $.5,3.5$, and $6.7 \mathrm{sec}$. First-interval response performance was superior at the 3.5 -sec ISI and second-interval response performance was superior at the 6.7-sec ISI. There appears, therefore, to be no single ISI function in SCR conditioning. In contrast to what happens with single-cue training, the conditional likelihood of a second-interval response was greater following the presence rather than the absence of a first-interval response. There was no evidence that the CS- acquired relative inhibitory properties, but the level of second-interval responding to CS- was approximately that of nonspecific response frequency and amplitude. This means that differential second-interval responding is almost exclusively a function of increased response levels to $\mathrm{CS}+$.

It is now well established that, with interstimulus intervals (ISIs) of 4 or $5 \mathrm{sec}$ or longer, multiple skin conductance responses (SCRs) are conditioned with both simple and differential conditioning preparations (see, e.g., reviews by Dengerink \& Taylor, 1971, and Prokasy \& Kumpfer, in press). In one study (Prokasy \& Ebel, 1967), it was demonstrated that the first-interval response (FIR) and the second-interval response (SIR) were statistically independent and that increases in conditioned stimulus (CS) intensity resulted in more frequent FIRs, but did not affect SIRs. One purpose of this study was to determine whether FIRs and SIRs, both occurring prior to the UCSs, were similarly independent within a differential conditioning paradigm.

A second purpose of this study was to assess the level of differential conditioning obtained as a function of ISI. FIRs are at a maximum magnitude and relative frequency at approximately a .5-sec ISI (see Gormezano \& Moore, 1969 , for summary), but what is not known is if maximum differential conditioning is similarly obtained at a .5 -sec ISI. Superior differential human eyelid conditioning performance is obtained (Hartman \& Grant, 1962) when the ISI is longer than that associated with higher levels of performance in a simple conditioning paradigm, but the longer latency of the FIR (minimum of $1.2 \mathrm{sec}$ vs minimum of $150 \mathrm{msec}$ ) may permit a maximum effect to occur even with the shorter ISI. Measuring both FIRs and SIRs across ISI also made it possible to determine whether or not differential conditioning was at a maximum for both responses at the same ISI.

*This study was supported by Grant MH 15353 from NIMH. It was conducted as a master's thesis by the senior author under direction of the junior author. Requests for reprints should be sent to William F. Prokasy, Department of Psychology, University of Utah, Salt Lake City, Utah 84112.

†Now at Utah State University.

\section{METHOD \\ Apparatus}

Two Ss were run simultaneously and in parallel in adjacent $2 \mathrm{x}$ $2 \mathrm{~m}$ chambers. Stimulus durations were controlled by Tektronix timers, and reinforced and nonreinforced trials were programmed by means of punched tapes for a Tally tape reader. Each S was fitted with a pair of Beckman $\mathrm{Ag} / \mathrm{AgCl}$ recording electrodes on the thenar and hypothenar eminence of the right palm. Responses were amplified and recorded on a Beckman Type $\mathrm{R}$ dynograph.

Two white lights, $13 \mathrm{~mm}$ in diam, served as the CS+ and CS-; each light was counterbalanced across cubicles. The UCS was a .2-sec burst of white noise delivered to the $S$ via a set of Koss headphones. The intensity of the UCS was $115 \mathrm{~dB}(\mathrm{~A})$.

Subjects

The Ss were 82 undergraduate students enrolled in introductory psychology classes at the University of Utah. An additional 16 Ss were lost due to apparatus failure, failure of the $\mathrm{S}$ to respond to the UCS, or E error.

\section{Design and Procedure}

The independent variable was ISI, with levels of $.5,3.5$, and 6.7 sec. Groups .5 and 6.7 contained 28 Ss, and Group 3.5, 26 Ss. In the first phase, habituation, Ss received 6 unpaired presentations each of the CS-, CS + , and UCS in an unsystematic order. The second phase, acquisition, followed immediately and was composed of 50 trials: $25 \mathrm{CS}$ - trials and $25 \mathrm{CS}+$ trials. Of the latter, 13 were paired with the UCS and 12 were not. The average intertrial interval was $40 \mathrm{sec}$, with values ranging from 30 to $50 \mathrm{sec}$ in steps of $5 \mathrm{sec}$. To obtain an index of nonspecific response levels, recordings were made during points of no stimulation on nine occasions randomly scattered through the session.

The Ss were seated in the experimental cubicle, and the recording electrodes were positioned. The $\mathrm{E}$ then played a recorded set of neutral instructions, which informed $S$ that the purpose of the experiment was to study sweat gland activity. After administering the instructions, $\mathrm{E}$ assigned Ss randomly to one of the three experimental groups and initiated stimulus presentation.

\section{Dependent Variable}

Two response intervals were defined by a latency criterion: 1.2 to $4.5 \mathrm{sec}$ and 4.5 to $7.8 \mathrm{sec}$ after CS onset. A response was classed as an FIR or an SIR if it was the first resistance change to occur in the respective latency intervals. The minimum response criterion for each $\mathrm{S}$ was a pen deflection representing anywhere from 400 to $4,000 \mathrm{ohms}$, depending on the sensitivity setting for each $S$. The sensitivity setting was related to S's responsiveness to the UCS, and for most Ss was either 400 or $800 \mathrm{ohms}$.

For each response category, the measures employed were probability and amplitude. As described earlier (Prokasy \& Ebel, 1967), amplitude is defined as the average size of a response given that the response criterion has been met.

\section{RESULTS AND DISCUSSION}

Other than a decrease in response probability across trials, no reliable between- or within-groups effects were observed during habituation, hence the analysis of these data will not be presented here. The .05 rejection region was employed in all statistical comparisons.

Table 1 provides response probability for all groups 
Table 1

Response Probability in Five Blocks of 10 Trials Each For FIR and SIR During Acquisition for Groups 5, 3.5, and 6.7

\begin{tabular}{|c|c|c|c|c|c|c|c|c|c|c|c|c|}
\hline \multirow{2}{*}{ 产 } & \multicolumn{6}{|c|}{$\begin{array}{c}\text { FIR } \\
\text { Trial Blocks }\end{array}$} & \multicolumn{6}{|c|}{$\begin{array}{c}\text { SIR } \\
\text { Trial Blocks } \\
\end{array}$} \\
\hline & $\mathrm{A}^{*}$ & 1 & 2 & 3 & 4 & 5 & $\mathrm{~A}^{*}$ & 1 & 2 & 3 & 4 & 5 \\
\hline $.5 \mathrm{CS}+$ & $\begin{array}{l}.512 \\
.476\end{array}$ & $\begin{array}{l}.545 \\
.438\end{array}$ & $\begin{array}{l}.607 \\
.482\end{array}$ & $\begin{array}{l}.464 \\
.491\end{array}$ & $\begin{array}{l}.464 \\
.469\end{array}$ & $\begin{array}{l}.512 \\
.402\end{array}$ & $\begin{array}{l}.131 \\
.179\end{array}$ & $\begin{array}{l}.152 \\
.116\end{array}$ & $\begin{array}{l}.107 \\
.143\end{array}$ & $\begin{array}{l}.143 \\
.161\end{array}$ & $\begin{array}{l}.143 \\
.107\end{array}$ & $\begin{array}{l}.071 \\
.134\end{array}$ \\
\hline $3.5 \begin{array}{l}\mathrm{CS}+ \\
\mathrm{CS}-\end{array}$ & $\begin{array}{l}.346 \\
.372\end{array}$ & $\begin{array}{l}.365 \\
.298\end{array}$ & $\begin{array}{l}.519 \\
.231\end{array}$ & $\begin{array}{l}.474 \\
.260\end{array}$ & $\begin{array}{l}.423 \\
.275\end{array}$ & $\begin{array}{l}.468 \\
.154\end{array}$ & $\begin{array}{l}.077 \\
.064\end{array}$ & $\begin{array}{l}.058 \\
.087\end{array}$ & $\begin{array}{l}.154 \\
.096\end{array}$ & $\begin{array}{l}.115 \\
.096\end{array}$ & $\begin{array}{l}.154 \\
.077\end{array}$ & $\begin{array}{l}.115 \\
.087\end{array}$ \\
\hline $\begin{array}{l}6.7 \mathrm{CS}+ \\
\mathrm{CS}- \\
\end{array}$ & $\begin{array}{l}.226 \\
.222 \\
\end{array}$ & $\begin{array}{l}.244 \\
.286 \\
\end{array}$ & $\begin{array}{l}.339 \\
.250 \\
\end{array}$ & $\begin{array}{l}.357 \\
.214 \\
\end{array}$ & $\begin{array}{l}.262 \\
.199 \\
\end{array}$ & $\begin{array}{l}.298 \\
.259 \\
\end{array}$ & $\begin{array}{l}.071 \\
.119 \\
\end{array}$ & $\begin{array}{l}.214 \\
.152 \\
\end{array}$ & $\begin{array}{l}.411 \\
.095 \\
\end{array}$ & $\begin{array}{l}.345 \\
.063 \\
\end{array}$ & $\begin{array}{l}.345 \\
.056 \\
\end{array}$ & $\begin{array}{l}.286 \\
.170 \\
\end{array}$ \\
\hline
\end{tabular}

${ }^{*} A=$ response probability for the last three trials in adaptation.

across five blocks of 10 trials each, as well as mean response probability just prior to the introduction of differential training. First interval response probability to CS+ increased somewhat in the initial trials and then either stabilized or decreased. Overall differential performance was not reliable in Group .5, but was reliable in Groups 3.5 and $6.7, t(25)=4.94$ and $t(27)=$ 2.28 , respectively. The largest difference was obtained in Group 3.5, this indicated by a reliable Groups by Stimuli interaction, $F(2,79)=4.05$.

In order to assess response amplitude (in units of $\sqrt{\mathrm{SCR}}$ in micromhos), only those Ss who made a minimum of one response in each of two blocks of 25 trials were employed. Mean FIR amplitude, and the resulting group Ns, are provided in Table 2. Amplitude was larger to $\mathrm{CS}+, \mathrm{F}(1,36)=22.86$, with the largest difference obtained in Group 3.5, this latter assessed by the Groups by Stimuli interaction, $F(2,36)=12.95$.

As suggested by Table 1, there was no reliable evidence of differential SIR conditioning in either Group .5 or Group 3.5; response probability remained constant across trial blocks and did not differ between CS+ and CS-. In Group 6.7, however, SIR probability increased and then slightly decreased over blocks, while no reliable changes to $\mathrm{CS}-$ were obtained. The overall CS,+ CS- difference was reliable, $t(27)=4.66$

Table 2 provides mean amplitude and group Ns for those Ss meeting a minimum response criterion of at least one SIR to each stimulus over the range of 50 trials. The only reliable amplitude effect was the difference between CS+ and CS- amplitudes in Group 6.7, $\mathrm{t}(21)=4.23$.

Two major points can be made based on these data. First, consistent with what has been obtained with the conditioned eyelid reflex (Hartman \& Grant, 1962), differential performance is greater at a longer ISI than is optimal in single-stimulus conditioning settings. Response probability in the latter case reaches a relative maximum with an ISI of $.5 \mathrm{sec}$, while the greatest differential conditioning performance was obtained at a longer ISI in the present study. Second, as Grings et al (1962) suggested, there is not a single function relating degree of conditioning and the ISI. This study shows quite clearly that the ISI at which maximal differential performance is obtained depends upon whether the FIR or the SIR is assessed. Differentially conditioned SIRs are not obtained with ISIs as short as $3.5 \mathrm{sec}$ but are with an ISI of $6.7 \mathrm{sec}$, an interval which, in this study, did not yield a large amount of differential FIR performance.

\section{FIR and SIR Interaction}

Since Group 6.7 yielded reliable differential FIR and SIR conditioning, it was possible to examine the relationships between them. This involved three statistical comparisons: likelihood of a SIR given the presence vs absence of a FIR; amplitude of a SIR given presence vs absence of a FIR; and the correlation between FIR and SIR amplitudes on a within-S basis. These analyses were conducted separately for CS+ and

Table 2

Mean FIR and SIR Probability and Amplitude Collapsed Over 50 Training Trials

\begin{tabular}{|c|c|c|c|c|c|c|c|c|}
\hline \multirow[b]{3}{*}{ ISI Group } & \multirow{2}{*}{\multicolumn{2}{|c|}{$\begin{array}{r}\text { All Ss } \\
\text { Probability } \\
\end{array}$}} & \multirow[b]{3}{*}{$\mathbf{N}$} & \multicolumn{5}{|c|}{ Criterion } \\
\hline & & & & \multicolumn{2}{|c|}{ Probability } & \multicolumn{2}{|c|}{ Amplitude } & \multirow[b]{2}{*}{$\mathrm{N}$} \\
\hline & $\mathrm{CS}+$ & $\mathrm{CS}-$ & & CS+ & $\mathrm{CS}-$ & CS+ & $\mathrm{CS}-$ & \\
\hline \multicolumn{9}{|l|}{ FIR } \\
\hline .5 & .518 & .456 & 28 & .599 & .580 & 1.330 & 1.293 & 13 \\
\hline 3.5 & .450 & .243 & 26 & .671 & .437 & 1.570 & 1.092 & 13 \\
\hline 6.7 & .300 & .241 & 28 & .479 & .359 & 1.152 & 1.100 & 13 \\
\hline \multicolumn{9}{|l|}{ SIR } \\
\hline .5 & .123 & .133 & 28 & .233 & .167 & .842 & 1.016 & 15 \\
\hline 3.5 & .116 & .091 & 26 & .192 & .153 & $\begin{array}{l}.042 \\
.910\end{array}$ & $\begin{array}{r}1.070 \\
.872\end{array}$ & 12 \\
\hline 6.7 & .319 & .107 & 28 & .350 & .127 & 1.571 & .969 & 21 \\
\hline
\end{tabular}


CS-. From among these comparisons, the only significant relationship obtained was that the likelihood of a SIR was greater following FIR (.627) than following the absence of a FIR $(.369), t(17)=3.90$. This result constitutes a departure from earlier work (Prokasy \& Ebel, 1967) in which it was found that with single-stimulus training the FIRs and SIRs were statistically independent. Thus, whether or not the FIRs and SIRs are statistically independent depends upon the conditioning preparation. Why the relationship should occur with differential conditioning is not clear. One possibility is that there is some general responsiveness contingent upon having differentiated $\mathrm{CS}+$ from $\mathrm{CS}-$, this reflecting itself in more than a chance relationship between FIRs and SIRs.

\section{Nonspecific Responding}

In one recent study (Prokasy, Williams, Kumpfer, Lee, \& Jenson, 1973), it was reported that SIR amplitude to $\mathrm{CS}+$ was greater than that to $\mathrm{CS}-$, and that the amplitude of responses made during time samples fell in between the two in value. Three stimuli were employed in that study, one of which (in addition to the CSt and CS-) had a random relationship to UCS occurrence, which could be both during and between stimuli. This study afforded an opportunity to examine nonspecific response amplitude to $\mathrm{CS}$ - and time samples in a typical differential conditioning paradigm.

Eleven Ss met a minimum SIR criterion of .1 to CSand during an equivalent period in time samples. Response probability under the two conditions was, respectively, .178 and .253 , the difference not reliable, $\mathrm{t}(11)=1.72$. SIR amplitude to $\mathrm{CS}-$ and time samples were, respectively, .982 and .850 , and this difference was not reliable, $t(11)=1.23$. Thus, an amplitude effect which was exhibited in a past experiment was not replicated. It is, or course, entirely possible that the context of the earlier experiment, involving as it did three stimuli with explicit instructions to $\mathrm{S}$ to attend to them, accounts for the difference. Regardless, it is clear that responding to $\mathrm{CS}$ - again does not exceed response levels obtained in the absence of stimulation. Differential SIR performance is determined by elevated response levels to $\mathrm{CS}+$, and the degree of differentiation is not reduced by response levels to $\mathrm{CS}-$

\section{REFERENCES}

Dengerink, H. A., \& Taylor, S. P. Multiple responses with differential properties in delayed galvanic skin response conditioning: A review. Psychophysiology, 1971, 8, 348-360.

Gormezano, I., \& Moore, J. W. Classical conditioning. In M. H. Marx (Ed.), Learning processes. Toronto: Macmillan, 1969. p. 121-203.

Hartman, T. F., \& Grant, D. A. Effects of pattern of reinforcement and verbal information on acquisition, extinction, and spontaneous recovery of the eyelid CR. Journal of Experimental Psychology, 1962, 63, 217-226.

Prokasy, W. F., \& Ebel, N. C. Three components of the classically conditioned GSR in human subjects. Journal of Experimental Psy chology, 1967, 73, 247-256.

Prokasy, W. F., \& Kumpfer, K. L. Classical conditioning. In W. F. Prokasy and D. C. Raskin (Eds.), Electrodermal activity in psychological research. New York: Academic Press, 1973. Pp. 157-202.

Prokasy, w. F., Williams, W. C., Kumpfer, K. L., Lee, W. Y., \& Jensen, W. R. Differential SCR conditioning with two control baselines: Random signal and signal absent. Psychophysiology, $1973,10,145-153$.

(Received for publication September 6, 1973.) 